\title{
Trunk Shaker Mechanical Harvesting Systems ${ }^{1}$
}

\section{S.H. Futch and F.M. Roka ${ }^{2}$}

As discussed in other documents regarding various aspects of mechanical harvesting, Florida citrus growers must adopt new technology to reduce harvesting costs, thus allowing our citrus industry to compete with low-wage countries in a global juice marketplace. Trunk shake systems are a viable mechanical harvesting system which growers should consider in an effort to lower harvesting costs, increase fruit returns, and remain competitive.

These mechanical harvesting systems have been used commercially for more than 10 years and have been extensively studied since the 1970 s.

Trunk shake systems are of two basic types, those which operate with a catch frame system (trunk shake and catch) (Figs. 1, 2, and 3) or systems without the catch frame (monoboom) (Fig. 4). Each of these systems offers different advantages and different savings potential in mechanically harvesting citrus fruit.

The trunk, shake and catch system utilizes two self-propelled units. On one side of the tree, a trunk shaker and a fruit deflector are combined into a single unit. In bedded groves, the shaking unit operates in the swale, or water furrow. The shaking unit clamps

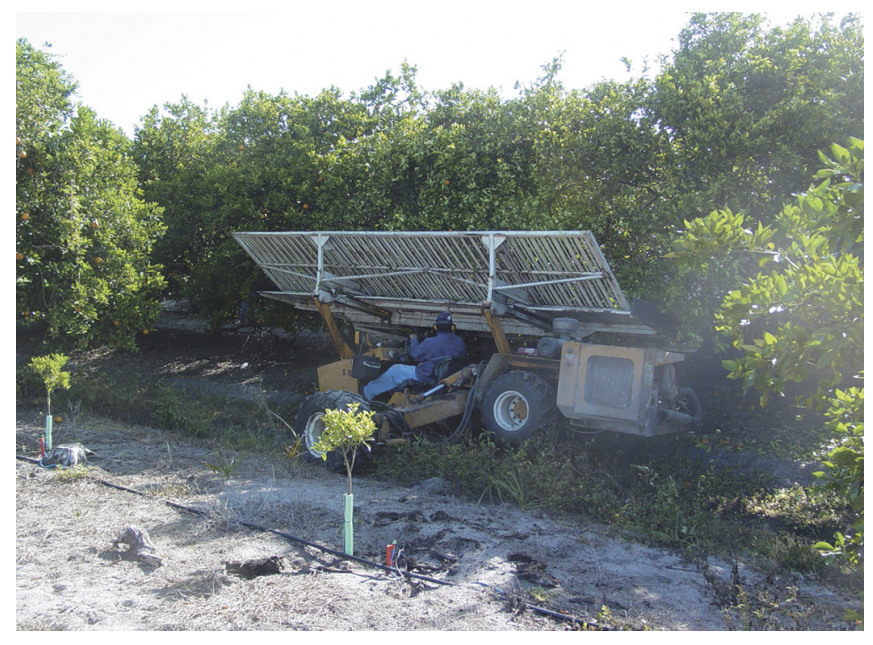

Figure 1. Coe-Collier shaker.

the tree trunk above the bud union and below the first scaffold limbs. A specially designed padded, particle-filled clamping pad shakes the tree with a straight-line linear direction. This straight-line shaking action is preferred to the multi-direction shaking system to minimize bark damage.

Actual shaking varies from 5 to 12 seconds depending upon the time of year and variety of fruit. Early in the season, when fruit pull-force measures are high, shake times may exceed 10 seconds.

1. This document is HS1005, one of a series of the Horticultural Sciences Department, Florida Cooperative Extension Service, Institute of Food and Agricultural Sciences, University of Florida. Published March 2005. This research was supported by the Florida Agricultural Experiment Station, and approved for publication as Journal Series No. T-00668. Visit the EDIS Web site at http://edis.ifas.ufl.edu.

2. S.H. Futch, extension agent IV, Horticultural Sciences Department, Citrus REC, Lake Alfred, Florida and F.M. Roka, associate professor, Food and Resource Economics Department, Southwest Florida REC, Immokalee, Florida; Cooperative Extension Service, Institute of Food and Agricultural Sciences, University of Florida, Gainesville, 32611.

The Institute of Food and Agricultural Sciences (IFAS) is an Equal Opportunity Institution authorized to provide research, educational information and other services only to individuals and institutions that function with non-discrimination with respect to race, creed, color, religion, age, disability, sex, sexual orientation, marital status, national origin, political opinions or affiliations. U.S. Department of Agriculture, Cooperative Extension Service, University of Florida, IFAS, Florida A. \& M. University Cooperative Extension Program, and Boards of County Commissioners Cooperating. Larry Arrington, Dean 


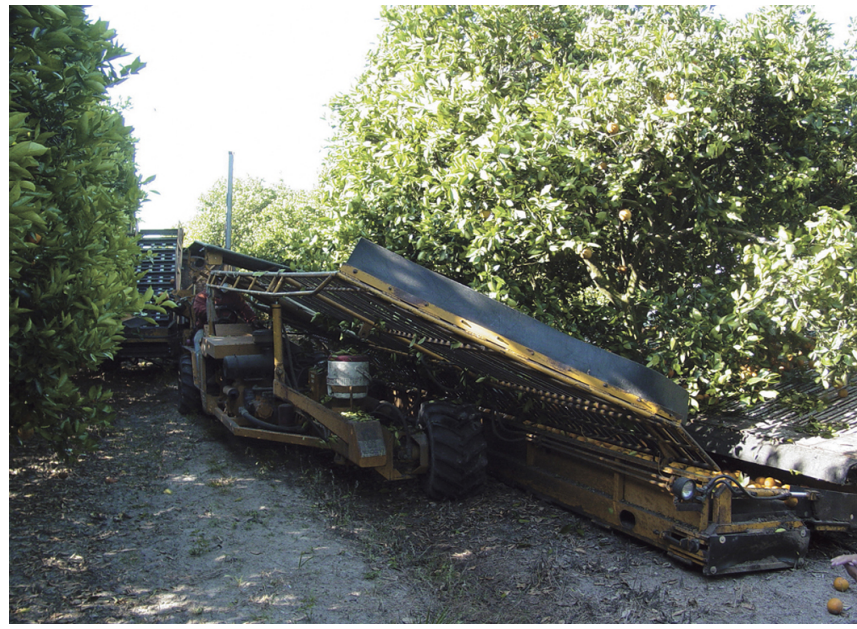

Figure 2. Coe-Collier receiver.

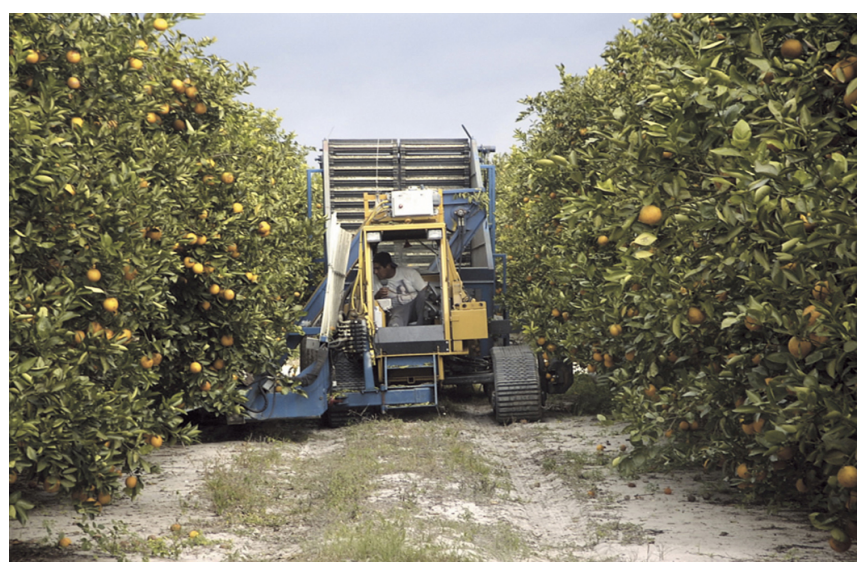

Figure 3. FMC trunk shaker.

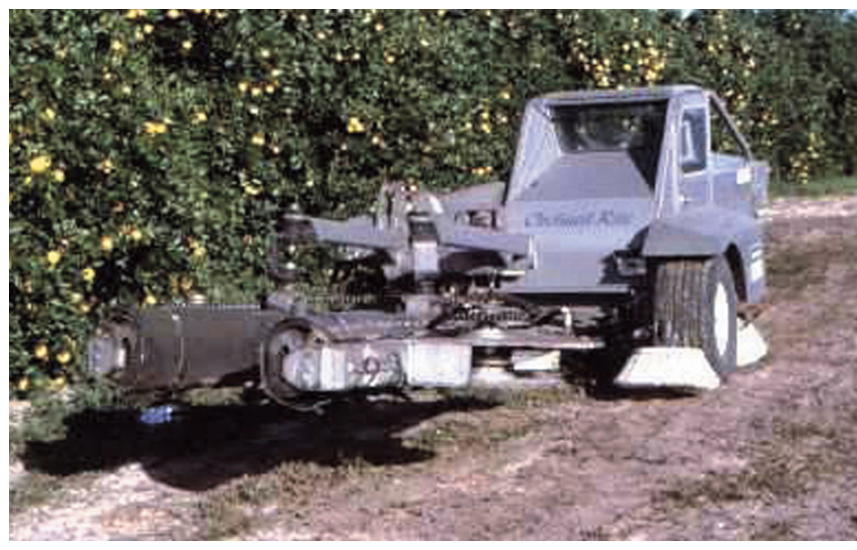

Figure 4. Stackhouse monoboom trunk shaker.

After shaking the tree, removed fruit is deflected to the receiving unit located on the opposite side of the tree. The receiving unit separates leaves and twigs and conveys fruit to a trailing cart. The cart holds between 80 to100 boxes before off-loading to a field goat. This harvesting system removes 94 to $97 \%$ of the fruit and recovers between 88 and $95 \%$ of the available fruit.
For optimum harvesting equipment efficiency, trunk spacing needs to be uniform down the row with clear trunk heights of at least 15 inches above the bud union. Skirting also improves harvest fruit removal and recovery. Low-hanging fruit that rides on the catch frame may remain attached to the tree or be raked off the catch frame before harvesting. Tree skirts should be at least 30 inches above the ground, measured on the bed and at the drip line, to allow the catch frame to easily slip under the tree canopy.

The trunk, shake and catch system is limited to trees with trunk diameter less than 10 inches. It is recommended that tree heights do not exceed 16 feet to minimize fruit splitting.

One set of trunk shakers can harvest between 90 to 140 trees per hour. Harvesting and roadside costs in the 2003-04 harvest season varied between $\$ 1.15$ to $\$ 1.60$ per field box depending upon tree preparation, yield, and gleaning requirements. In many cases, growers using this system have saved between 20 to 50 cents per box as compared to growers using conventional harvesting systems. In years with low fruit prices, gleaning operations may not be economically feasible or justified.

The other trunk shake system is referred to as the monoboom trunk shake system. This monoboom trunk shake system operates without the catch frame. The monoboom mechanical harvesting system has greater flexibility operating in groves where the trunk shake and catch systems are not suited due to trunk size, grove design or low-hanging limbs. The monoboom system is well suited for older groves with trees that have short trunks or trunks with a diameter of greater than 9 inches. The monoboom can clamp on to larger limbs if necessary.

Seedling trees as high as 25 feet have been harvested with monoboom trunk shakers. When shaking large trees, it is recommended that the grove floor be disked to cushion falling fruit and minimize splitting. The monoboom system operates in the drive middle and zigzags to harvest trees on both the right and left side of the machine as it travels down the row.

Since the machine does not use a catch frame, the fruit is allowed to drop to the ground where a hand 
crew picks up the fruit and gleans fruit from lower branches. The system can shake between 30 to 100 trees per hour.

Harvesting cost savings from using the monoboom system are generally not as great as compared to the trunk, shake and catch system because hand labor is required to pick the fruit from the ground, thereby reducing the cost savings. This system does increase the efficiency of hand labor, however, because more fruit per hour can be gathered by picking it up by hand from the ground than by harvesting it by hand from the tree.

Growers should consider other factors to improve harvesting efficiencies when using trunk shakers. Microjet irrigation systems should be low to the ground, within the trunk-line of the row, and midway between adjacent trees. As mentioned above, skirting the trees to a height of 30 inches allows the catch frame to move easily under the tree canopy and minimizes tree damage.

From research conducted by the University of Florida, the United States Department of Agriculture, the Florida Department of Citrus and harvesting companies, groves harvested for 10 or more years show no evidence of shortened tree life or reduced yields. Bark damage to the tree trunk has been noted in some cases when the tree's cambium is actively growing. Damage can be minimized with proper operator training and properly designed and operated equipment.
At the present time, the main operator of these trunk shake systems is Coe-Collier Citrus Harvesting of Immokalee. Additionally, Food Machinery Corporation (FMC) is actively developing and operating equipment in south Florida. In previous years, the monoboom trunk shaker was operated in the state but has not operated in the 2003-04 season.

Mechanical harvesting systems have been used successfully in Florida citrus groves. These systems reduce harvesting costs, thus allowing the citrus industry to remain competitive in a global juice market.

Table 1. Trunk Shake Mechanical Harvester Contractors

\begin{tabular}{||lccc||}
\hline \hline Company & City & Contact & Phone Number \\
\cline { 2 - 4 } Coe-Collier & Immokalee, FL & Will Elliot & 239-658-6074 \\
FMC FoodTech & Lakeland, FL & John Crum & 863-499-1823 \\
Stackhouse Harvesting & Hickman, CA & Matt Craven & $863-441-0911$ \\
\hline \hline
\end{tabular}

